\title{
A TEORIA DO REGISTRO DE REPRESENTAÇÃO SEMIÓTICA: O UNIVERSO MATEMÁTICO DAS OPERAÇÕES COM FRAÇÕES
}

doi>10.33726/akdpapers2447-7656v8a52019p108-129

\author{
SANTOS, Geisiane Rodrigues dos ${ }^{1}$
}

RESUMO: O objetivo deste estudo é o de apresentar um processo de ensino que é subsidiado por aspectos relacionados à Teoria dos Registros de Representação Semiótica, de Raymond Duval. Nesta abordagem, o teórico pondera, dizendo que as dificuldades enfrentadas pelos mais diversos estudantes, em diferentes representações de um objeto matemático, podem ser resolvidas por meio de sua Teoria. A presente proposta, então, se relaciona com o ensino dos racionais e suas representações. $O$ corpus investigativo se deu a partir de um recorte que priorizou os estudantes do $6^{\circ}$ ano do Ensino Fundamental, de uma escola pública de Minas Gerais - MG. Analisou-se inicialmente o conhecimento prévio dos alunos sobre frações e a percepção de que qualquer unidade pode ser dividida em partes menores e iguais. Posteriormente, a compreensão correspondente a numerador e denominador e, por último, a execução de atividades que transitaram por distintos registros de representações semióticas. Como resultados preliminares, verificamos que os alunos não obtiveram "sucesso" no desenvolvimento da terceira atividade, por desconheceres as diversas formas de representação do modelo matemático proposto e por apresentarem dificuldades em efetuar a divisão entre dois números.

PALAVRAS-CHAVE: Registro de representação semiótica, habilidades e competências, números racionais

ABSTRACT: The aim of this study is to present a teaching process that is supported by aspects related to Raymond Duval's Theory of Semiotic Representation Records. In this approach, or theoretical pond, saying that the difficulties are faced by the most diverse students, in different representations of a mathematical object, can be solved through their theory. The present proposal, then, relates to the teaching of rationals and their representations. The investigative corpus was based on a cut that prioritized the students of the 6th grade of elementary school, from a public school in Minas Gerais - MG. The students' prior knowledge of fractions and the perception that any unit can be divided into smaller and equal parts were initially analyzed. Subsequently, the understanding corresponding to numerator and denominator and, finally, the execution of activities that transited through different registers of semiotic representations. As preliminary results, we found that the students did not have "success" in the development of the third activity, because they are unaware of the various forms of representation of the proposed mathematical model and have difficulties in dividing between two numbers.

KEYWORDS: Record of semiotic representation, skills and competences, rational numbers

Doutoranda em Educação Matemática pela Universidade Anhanguera, de São Paulo. Bolsista FAPEMIG/PCRH, 2018-2020. Professora do Departamento de Ciências Exatas e da Terra, da Universidade do Estado de Minas Gerais - UEMG, Unidade Frutal. 


\title{
INTRODUÇÃO
}

O estudo dos números racionais, em específico o caso das frações, tal como qualquer outro conteúdo da Matemática, está associado à aprendizagem, a qual requer um conhecimento que não se fundamenta na mera memorização de definições e regras, e que, portanto, não acarreta significado algum ao aluno.

Conforme a proposta da "Matriz Curricular para o Ensino de Matemática nos Anos Iniciais do Ensino Fundamental de Minas Gerais" (2014, p.14), nas suas orientações pedagógicas, se preveem atividades com o emprego de materiais concretos, o que possibilita um entendimento das ideias dos números racionais:

\begin{abstract}
A característica principal do início do trabalho com frações é o nível concreto em que se realizam as atividades. Permitir que o aluno perceba a necessidade dos números racionais e o seu estudo introduzindo problemas associados às ideias de "repartir em partes iguais" e de medida, isto é "de quantas vezes uma unidade de medida cabe no objeto que está sendo medido.
\end{abstract}

A apreensão do conteúdo também está associada à forma com que o professor inicia e conduz o processo de ensino e conduz as intervenções durante as aulas. Ainda de acordo com a Matriz Curricular (2014, p.14), verifica:

\begin{abstract}
Uma estratégia que pode ser interessante para que os alunos do Ensino Fundamental percebam as questões acima discutidas é escolher problemas, de preferência contextualizados, cuja resolução se torne mais ou menos trabalhosa, dependendo da forma de representação (decimal ou fracionária) escolhida para as operações correspondentes.
\end{abstract}

Nesse sentido, ao contextualizar a atividade, o professor ajuda o aluno a estabelecer as relações, problematizar, além de motivar a sua capacidade de procurar soluções.

Segundo a Matriz Curricular, as Capacidades e Habilidades que se almeja a aprendizagem das frações, de alunos do $5^{\circ}$ ano, são:

Reconhecer frações unitárias usuais (um meio, um terço, um quarto e um décimo) de quantidades contínuas e discretas em situação de 
contexto familiar, sem recurso à representação simbólica. [...] Explorar diferentes significados das frações em situações-problema. Analisar, interpretar, formular e resolver situações-problema, compreendendo diferentes significados da adição, subtração, multiplicação e divisão envolvendo números racionais escritos na forma decimal, por meio de estratégias pessoais e técnicas operatórias convencionais. [...] (2014, p. 37).

Outrossim, dentre as Capacidades e Habilidades, almeja-se a aprendizagem dos seguintes Conteúdos (2014, p.40), para os alunos do $5^{\circ}$ ano, sendo eles:

- Noção intuitiva de fração a partir do contexto da coleção (metade, quarta parte e outras);

- Conceito de fração (noção de conservação de quantidades; compreensão das relações do todo com suas partes; percepção de que qualquer unidade pode ser dividida em partes menores do mesmo tamanho ou valor);

- A terminologia correspondente: numerador, denominador e seus significados; [...]

- A associação de uma fração à sua representação decimal e viceversa;

- As operações com números racionais em forma decimal e fracionária: adicionar, multiplicar, subtrair e dividir;

- Resolver problemas que envolvam números racionais; e,

- Localizar números racionais na reta numérica.

Essas propostas estão presentes nas diretrizes curriculares e, dentre os diversos problemas estudados em Educação Matemática, no que se refere ao ensino e a aprendizagem de Matemática, buscou-se analisar no presente trabalho, em três etapas, o conhecimento prévio dos alunos sobre frações, no que se refere à percepção de como qualquer unidade pode ser dividida em partes menores do mesmo tamanho ou valor; a compreensão de numerador e denominador e, por último, passagem por diferentes registros de representações semióticas.

Dessa forma, é necessário tecer algumas considerações acerca dessa proposta, quando duas representações distintas interagem e podem representar um mesmo objeto matemático. 


\section{REGISTROS DE REPRESENTAÇÃO SEMIÓTICA}

A partir da década de 70, Raymond Duval, filósofo e psicólogo francês, realizou estudos no Instituto de Pesquisa em Educação Matemática, no campo da psicologia cognitiva, contribuindo com o ensino de Matemática (FREITAS e REZENDE, 2013). Envolvido em estudos que considerava o processo de ensino e aprendizagem, desenvolveu a "Teoria dos Registros de Representação Semióticas", a qual tem alavancado pesquisas relativas à apreensão do conhecimento, sendo em muitas situações, o suporte metodológico, além de subsidiar circunstâncias de aprendizagem (BARROS, 2011).

Para Duval, atividades que envolvem descrição, raciocínio e visualização em matemática facilitam a sua aprendizagem e, assim estão ligadas aos registros de representação semiótica (FLORES, 2014).

No campo cognitivo, dentro da teoria dos registros de representação semiótica, para se compreender um dado conteúdo da matemática é necessário que o aluno saiba representar de diversas maneiras um mesmo conceito, ou seja:

É necessário que os estudantes estejam mais habituados a fazer estas conversões e tratamentos entre as mais variadas formas de representações dos objetos matemáticos, para que não sintam uma dificuldade tão elevada, conseguindo identificar em cada uma das representações, formas diferenciadas de escrever o objeto matemático (LENARTOVICZ e GAERTNER, p. 05).

Por sua vez, segundo Barros (2011, p. 34), "a Semiótica é a ciência ligada a signos e símbolos que têm a função de comunicação". Desse modo, essas relações estão estabelecidas a partir do momento que o aluno consegue aprender os sentidos que se estabelecem a partir das relações entre os signos e os símbolos.

O sistema semiótico é, portanto, constituído a partir do momento em que ocorrem articulações entre os signos, dentro de um conjunto de regras específicas. Logo, "representar um objeto significa criar uma cópia ou produzir alguma expressão que lembre esse objeto" (grifo do autor).

Os signos são representações da linguagem natural, da língua formal, da escrita algébrica, das representações gráficas ou das figuras. 
Segundo Barros (2011), dentro de uma representação semiótica pode ocorrer duas transformações cognitivas: o tratamento e a conversão.

O tratamento ocorre quando uma representação, dentro do sistema semiótico onde se produziu, transforma em outra representação que não acarreta mudanças da forma e do conteúdo de um objeto matemático. Já, a conversão, ocorre se essa transformação muda a sua forma, modificando o sistema semiótico e não altera o conteúdo.

Se ocorrer dentro de um sistema semiótico transformações cognitivas, como a produção, o tratamento e a conversão, tem-se um registro de uma representação semiótica. De acordo Friederich (2010, p. 79):

QUADRO 6: A distinção entre tratamento e conversão

\begin{tabular}{|c|c|}
\hline \multicolumn{2}{|c|}{$\begin{array}{l}\text { Transformação } \\
\text { De uma representação semiótica em } \\
\text { uma outra representação semiótica }\end{array}$} \\
\hline $\begin{array}{l}\text { Permanecendo o mesmo sistema: } \\
\text { TRATAMENTO }\end{array}$ & $\begin{array}{c}\text { Mudando de sistema, mas conservando a } \\
\text { referência aos mesmos objetos: } \\
\text { CONVERSÃO }\end{array}$ \\
\hline $\begin{array}{l}\text { Quase sempre é somente esse tipo de transformação } \\
\text { que chama atenção porque ele corresponde a } \\
\text { procedimentos de justificação. De um ponto de vista } \\
\text { "pedagógico", tenta-se algumas vezes procurar o } \\
\text { melhor registro de representação a ser utilizado para } \\
\text { que os alunos possam compreender. }\end{array}$ & $\begin{array}{l}\text { Esse tipo de transformação enfrenta os feno- } \\
\text { menos de não-congruência. Isso se traduz } \\
\text { pelo fato de os alunos não reconhecerem o } \\
\text { mesmo objeto através de duas representações } \\
\text { diferentes. A capacidade de converter implica } \\
\text { a coordenação de registros mobilizados. Os } \\
\text { fatores de não-congruência mudam con- } \\
\text { forme os tipos de registro entre as quais a } \\
\text { a conversão é ou deve ser efetuada. }\end{array}$ \\
\hline
\end{tabular}

(DUVAL, 2003)

Figura 1 - Tratamento e conversão

Os registros, quanto à sua natureza, podem ser monofuncionais ou multifuncionais. Os multifuncionais são os processos oriundos de diversas áreas da cultura, utilizados tanto para fins de comunicação como tratamento. De acordo com Barros (2011), eles não são algoritmizáveis, apesar de apresentar várias formas de tratamento. Já os monofuncionais, são aqueles registros criados a partir da necessidade de um tratamento específico, com o objetivo de melhorar os desempenhos.

Com relação à sua discursividade, eles podem ser podem ser discursivos ou não discursivos. Barros (2011, p. 35) afirma que os registros de representação semiótica são de quatro tipos: 
Registros da língua natural (discursivos e multifuncionais)

Registros figurais (não discursivos e multifuncionais)

Registros simbólicos (discursivos e monofuncionais)

Registros gráficos (não discursivos e monofuncionais)

(grifo do autor)

De acordo com Duval (2003, apud FRIEDERICH, 2010, p. 78), os registros de representação semiótica podem ser classificados a partir do seu funcionamento matemáticos, são eles:

QUADRO 5: Classificação dos diferentes registros mobilizáveis na atividade

matemática.

\begin{tabular}{|c|c|c|}
\hline & $\begin{array}{l}\text { REPRESENTAÇÃO } \\
\text { DISCURSIVA }\end{array}$ & $\begin{array}{l}\text { REPRESENTAÇÃO NÃO- } \\
\text { DISCURSIVA }\end{array}$ \\
\hline $\begin{array}{l}\text { REGISTROS } \\
\text { MULTIFUNCIONAIS } \\
\text { (não-algoritmizáveis) }\end{array}$ & $\begin{array}{l}\text { Língua Natural } \\
\text { Associações verbais } \\
\text { (conceituais) } \\
\text { Formas de Raciocinar: } \\
\text { - Argumentos a partir } \\
\text { de observações, de crenças; } \\
\text { - Dedução válida a } \\
\text { partir de definição ou de } \\
\text { teoremas. }\end{array}$ & $\begin{array}{l}\text { Figuras geométricas planas ou } \\
\text { em perspectivas (configurações } \\
\text { em dimensão } 0,1,2 \text { ou } 3 \text { ). } \\
\text { • Apreensão operatória e } \\
\text { não somente perceptiva; } \\
\text { • Construção } \\
\text { instrumentos. com }\end{array}$ \\
\hline $\begin{array}{l}\text { REGISTROS } \\
\text { MONOFUNCIONAIS } \\
\text { (algoritmizáveis) }\end{array}$ & \begin{tabular}{l}
\multicolumn{3}{l}{ Sistemas de Escritas: } \\
- Numéricas(binária, \\
decimal, fracionária...); \\
- Algébricas; \\
formais). Simbólicas (línguas \\
- Cálculo.
\end{tabular} & $\begin{array}{l}\text { Gráficos Cartesianos: } \\
\text { • Mudanças } \\
\text { coordenadas; } \\
\text { • Interpolação, } \\
\text { exploração. }\end{array}$ \\
\hline
\end{tabular}

(DUVAL, 2003)

Figura 2 - Classificação dos Diferentes Fegistros de Representação Semiótica

Duval (2013, p. 27), só ocorre aquisição de conhecimentos quando o aluno consegue oscilar naturalmente por divergentes registros de representação, ou seja, "é preciso primeiro tomar consciência das transformações de representações semióticas, por meio de mudanças de registros e pelos tratamentos específicos de cada registro". 


\section{A PROPOSTA}

A atividade foi desenvolvida com alunos do $6^{\circ}$ ano, de uma escola pública do interior de Minas Gerais. O trabalho foi aplicado no dia 10 de junho de 2014, com o objetivo de identificar os conhecimentos prévios sobre frações e suas possíveis representações.

A aplicação da sequência foi realizada em três atividades. As atividades foram posteriormente analisadas e confrontadas com o diário de campo da pesquisadora (observação da mobilização dos alunos) e, a partir deles, as conclusões foram elaboradas.

\section{APLICAÇÃO DAS ATIVIDADES}

A professora da turma entregou para cada aluno, 18 recortes retangulares e explicou que cada recorte retangular representaria um bolo inteiro de mesmo formato, utilizados para responder as três atividades. Explicou que os recortes retangulares correspondiam aos bolos inteiros da situação-problema.

Desenvolvemos uma sequência composta por três etapas. Na primeira etapa, o enunciado elucida uma situação-problema que retrata uma fração aparente (frações em que o numerador é múltiplo do denominador). Na segunda etapa, o enunciado elucida uma situação-problema em que se retrata uma fração própria (fração em que o numerador é menor que o denominador). Na terceira etapa, o enunciado elucida uma situação-problema em que retrata uma fração imprópria (fração onde o numerador é maior que o denominador).

\section{Proposta 01:}

\section{Primeira atividade:}

Situação-problema:

Usando a folha de papel e os recortes, repartir 12 bolos entre 03 crianças, sendo elas, Flávia, Paula e Pedro

a) Represente o resultado da divisão com recortes

b) Faça o algoritmo da divisão

c) Qual a fração que representa o enunciado? 
d) Qual o significado do quociente nessa divisão?

e) Qual o significado do resto nessa divisão?

f) As crianças receberam apenas bolos inteiros? Justifique

\section{Quadro 01 - Resolução esperada da primeira atividade}

\begin{tabular}{|c|c|c|c|}
\hline Representação & Alternativa & Registro & Tipo de Registro \\
\hline Paula Pedro & $a$ & Registro Figural & $\begin{array}{c}\text { Figural (não } \\
\text { discursivos e } \\
\text { Multifuncionais) }\end{array}$ \\
\hline$\frac{12\lfloor 3}{\frac{-12}{00}}$ & & $\begin{array}{l}\text { Registro Simbólico } \\
\text { (algoritmo da divisão) }\end{array}$ & $\begin{array}{l}\text { Simbólico } \\
\text { (Discursivos e } \\
\text { Monofuncional) }\end{array}$ \\
\hline$\frac{\frac{\mathrm{R} 3}{12}}{3}$ & C & $\begin{array}{l}\text { Registro Simbólico } \\
\text { (Numérico- } \\
\text { Fracionário) }\end{array}$ & $\begin{array}{c}\text { Simbólico } \\
\text { (Discursivos e } \\
\text { Monofuncional) }\end{array}$ \\
\hline $\begin{array}{l}\text { O significado do quociente: cada } \\
\text { crianca receberá } 4 \text { bolos inteiros. }\end{array}$ & & $\begin{array}{c}\text { Registro da língua } \\
\text { natural }\end{array}$ & $\begin{array}{l}\text { Língua Natural } \\
\text { (discursivos e } \\
\text { Multifuncionais) }\end{array}$ \\
\hline $\begin{array}{l}\text { O significado do resultado: não } \\
\text { existem mais bolos inteiros para } \\
\text { serem divididos. }\end{array}$ & e & $\begin{array}{c}\text { Registro da língua } \\
\text { natural }\end{array}$ & $\begin{array}{l}\text { Língua Natural } \\
\text { (Discursivos e } \\
\text { Multifuncionais) }\end{array}$ \\
\hline $\begin{array}{c}\text { As crianças receberam apenas bolos } \\
\text { inteiros? Justifique } \\
\text { As crianças receberam } 4 \text { bolos } \\
\text { inteiros. }\end{array}$ & $f$ & $\begin{array}{l}\text { Registro da língua } \\
\text { natural }\end{array}$ & $\begin{array}{l}\text { Língua Natural } \\
\text { (discursivos e } \\
\text { Multifuncionais) }\end{array}$ \\
\hline
\end{tabular}

Assim que a atividade fosse completa, os alunos "deveriam" possuir apenas 06 recortes retangulares, para as duas últimas atividades propostas, as quais correspondiam aos bolos da situação-problema.

\section{Proposta 02:}

\section{Segunda atividade:}

Situação-problema: Usando a folha de papel e os recortes, repartir 01 bolo entre 03 crianças, sendo elas, Flávia, Paula e Pedro

g) Represente o resultado da divisão com recortes

h) Faça o algoritmo da divisão. 
i) Qual a fração que representa o enunciado?

j) Qual o significado do quociente nessa divisão?

k) Qual o significado do resto nessa divisão?

l) As crianças receberam apenas bolos inteiros? Justifique

Quadro 2 - Resolução esperada da segunda atividade

\begin{tabular}{|c|c|c|c|}
\hline Representação & Alternativa & Registro & Tipo de Registro \\
\hline $\begin{array}{ccc}\text { Flávia } & \text { Paula } & \text { Pedro } \\
\square & \square & \square\end{array}$ & g & Registro Figural & $\begin{array}{l}\text { Figural (não } \\
\text { discursivos e } \\
\text { Multifuncionais) }\end{array}$ \\
\hline$\frac{\mathrm{R2}}{\mathrm{L}_{3}}$ & h & $\begin{array}{l}\text { Registro Simbólico } \\
\text { (algoritmo da divisão) }\end{array}$ & $\begin{array}{l}\text { Simbólico (Discursivos } \\
\text { e Monofuncional) }\end{array}$ \\
\hline$\frac{\mathrm{R3}}{\frac{1}{3}}$ & & $\begin{array}{c}\text { Registro Simbólico } \\
\text { (Numérico-Fracionário) }\end{array}$ & $\begin{array}{c}\text { Simbólico } \\
\text { (Discursivos e } \\
\text { Monofuncional) }\end{array}$ \\
\hline $\begin{array}{l}\text { O significado do quociente: } \\
\text { cada criança receberá } 0 \text { bolo } \\
\text { inteiro. }\end{array}$ & & $\begin{array}{c}\text { Registro da língua } \\
\text { natural }\end{array}$ & $\begin{array}{l}\text { Língua Natural } \\
\text { (discursivos e } \\
\text { Multifuncionais) }\end{array}$ \\
\hline $\begin{array}{c}\text { O significado } \frac{\mathbf{R} 5}{\text { do }} \text { resto: haverá } \\
1 \text { bolo para ser repartido entre } \\
3 \text { crianças }\end{array}$ & k & $\begin{array}{c}\text { Registro da língua } \\
\text { natural }\end{array}$ & $\begin{array}{l}\text { Língua Natural } \\
\text { (discursivos e } \\
\text { Multifuncionais) }\end{array}$ \\
\hline $\begin{array}{c}\text { As crianças receberam apenas } \\
\text { bolos inteiros? Justifique } \\
\text { Nenhuma criança recebeu } \\
\text { bolos inteiros }\end{array}$ & & $\begin{array}{c}\text { Registro da língua } \\
\text { natural }\end{array}$ & $\begin{array}{l}\text { Língua Natural } \\
\text { (discursivos e } \\
\text { Multifuncionais) }\end{array}$ \\
\hline
\end{tabular}

Os alunos "deveriam" possuir apenas 05 recortes retangulares para a última atividade proposta, que correspondia aos bolos da situação-problema. Se o aluno não conseguiu retirar 13 recortes dentre os 18 , poderia ter a situação de estar faltando recortes ou ter um número maior de recortes.

\section{Proposta 03:}

\section{Terceira atividade:}

Situação-problema: Usando a folha de papel e os recortes, repartir 05 bolos entre 03 crianças, sendo elas, Flávia, Paula e Pedro

m) Represente o resultado da divisão com recortes.

n) Faça o algoritmo da divisão.

o) Qual a fração que representa o enunciado?

p) Qual o significado do quociente nessa divisão?

q) Qual o significado do resto nessa divisão?

r) As crianças receberam apenas bolos inteiros? Justifique 
Quadro 3 - Resolução esperada da terceira atividade

\begin{tabular}{|c|c|c|c|}
\hline Representação & Alternativa & Registro & $\begin{array}{c}\text { Tipo de } \\
\text { Registro }\end{array}$ \\
\hline $\begin{array}{lll}\text { Flávia } & \text { R1 } & \\
\text { Jedro } & \square \square & \text { Paula } \\
\square \square & \square \square \square\end{array}$ & & Registro Figural & $\begin{array}{c}\text { Figural (não } \\
\text { discursivos e } \\
\text { Multifuncionais) }\end{array}$ \\
\hline $\begin{array}{r}\frac{\mathrm{R} 2}{5} 3 \\
-\quad 3 \frac{1}{2}\end{array}$ & n & $\begin{array}{l}\text { Registro Simbólico } \\
\text { (algoritmo da divisão) }\end{array}$ & $\begin{array}{c}\text { Simbólico } \\
\text { (Discursivos e } \\
\text { Monofuncional) }\end{array}$ \\
\hline$\frac{\frac{\mathrm{R3}}{5}}{3}$ & 0 & $\begin{array}{c}\text { Registro Simbólico } \\
\text { (Numérico-Fracionário) }\end{array}$ & $\begin{array}{c}\text { Simbólico } \\
\text { (Discursivos e } \\
\text { Monofuncional) }\end{array}$ \\
\hline $\begin{array}{l}\text { O significado do quociente: } \\
\text { cada criança receberá } 1 \\
\text { bolo inteiro. }\end{array}$ & & $\begin{array}{c}\text { Registro da língua } \\
\text { natural }\end{array}$ & $\begin{array}{l}\text { Língua Natural } \\
\text { (discursivos e } \\
\text { Multifuncionais) }\end{array}$ \\
\hline $\begin{array}{l}\text { O significado do resto da } \\
\text { divisão: ainda existirá } 2 \\
\text { bolos inteiros para serem } \\
\text { divididos em } 3 \text { crianças }\end{array}$ & & $\begin{array}{c}\text { Registro da língua } \\
\text { natural }\end{array}$ & $\begin{array}{l}\text { Língua Natural } \\
\text { (discursivos e } \\
\text { Multifuncionais) }\end{array}$ \\
\hline $\begin{array}{c}\text { R6 } \\
\text { As crianças receberam } \\
\text { apenas bolos inteiros? } \\
\text { Justifique } \\
\text { As criança receberam } 1 \\
\text { bolo inteiro e } 2 / 3 \text { pedaços } \\
\text { de bolos. } \\
\end{array}$ & & $\begin{array}{c}\text { Registro da língua } \\
\text { natural }\end{array}$ & $\begin{array}{l}\text { Língua Natural } \\
\text { (discursivos e } \\
\text { Multifuncionais) }\end{array}$ \\
\hline
\end{tabular}

Os alunos "deveriam" não ter mais recortes retangulares para completar essa última atividade proposta. Havendo falha em alguns dos processos, o aluno teria problemas em completar as atividades.

\section{ANÁLISE DA PROPOSTA}

As três atividades foram elaboradas com o objetivo de proporcionar ao aluno a conversão do registro da língua natural para o registro figural. No caso, a conversão foi realizada através da representação no plano (R1), ocorrendo a representação identificável do registro dado.

$\mathrm{Na}$ atividade $\mathrm{R} 1$ com R2, existe uma conversão, pois o aluno não consegue reconhecer o mesmo objeto (Registro figural) e o Registro Simbólico (algoritmo da divisão). 
Na situação, por exemplo, em que o aluno realiza o algoritmo da divisão (R2) ou que ele representa a fração, corresponde à situação problema (R3), e ele está fazendo uma conversão, por serem transformações dentro de registros diferentes.

$\mathrm{Na}$ situação em que o aluno responde (R4), referente ao (R2), ele está fazendo uma conversão, pois ele passou do registro simbólico (algoritmo) para o registro da língua natural, conservando os mesmos objetos.

$\mathrm{Na}$ situação em que o aluno responde (R5) referente ao (R2) e a (R4), ele está fazendo uma conversão, pois ele passou do registro do algoritmo escrito para o registro da língua natural, conservando os mesmos objetos e, também, um tratamento por realizar transformações dentro de um mesmo registro.

Dentro da matemática, tais transformações se fazem necessárias, pois os objetos matemáticos de estudos são abstratos. As representações permitem o estudo desses elementos, sendo importante transitar dentro dos diferentes registros, para que ocorra uma compreensão do objeto matemático em estudo.

Assim, com a representação de seus objetos se constitui no conhecimento matemático de representar um objeto matemático, e isso se difunde, muitas vezes, na ideia do objeto matemático per se.

\section{ANÁLISE PARCIAL DOS RESULTADOS}

Para exemplificar as considerações descritas acima, apresentaremos a seguir os dados categorizados, a partir da aplicação da atividade em sala de aula.

\section{Tabela 1 - Resultados da Primeira Atividade}

\begin{tabular}{c|c|c}
\multicolumn{3}{|c}{ Alternativa a } \\
\hline Categoria & $\begin{array}{c}\text { Número de } \\
\text { ocorrências }\end{array}$ & Frequência (\%) \\
\hline Acertos & 20 & 80 \\
Erro Tipo 1 & 2 & 8 \\
Erro Tipo 2 & 3 & 12 \\
\hline Total & $\mathbf{2 5}$ & $\mathbf{1 0 0}$ \\
\hline
\end{tabular}


Optamos por categorizar os erros, que para descrevê-los, primeiramente, seria necessário realizar uma contagem do número de ocorrências de cada tipo, ou seja, agrupamos os mesmos tipos de erros para apresentarmos. A figura 1 representa os acertos:

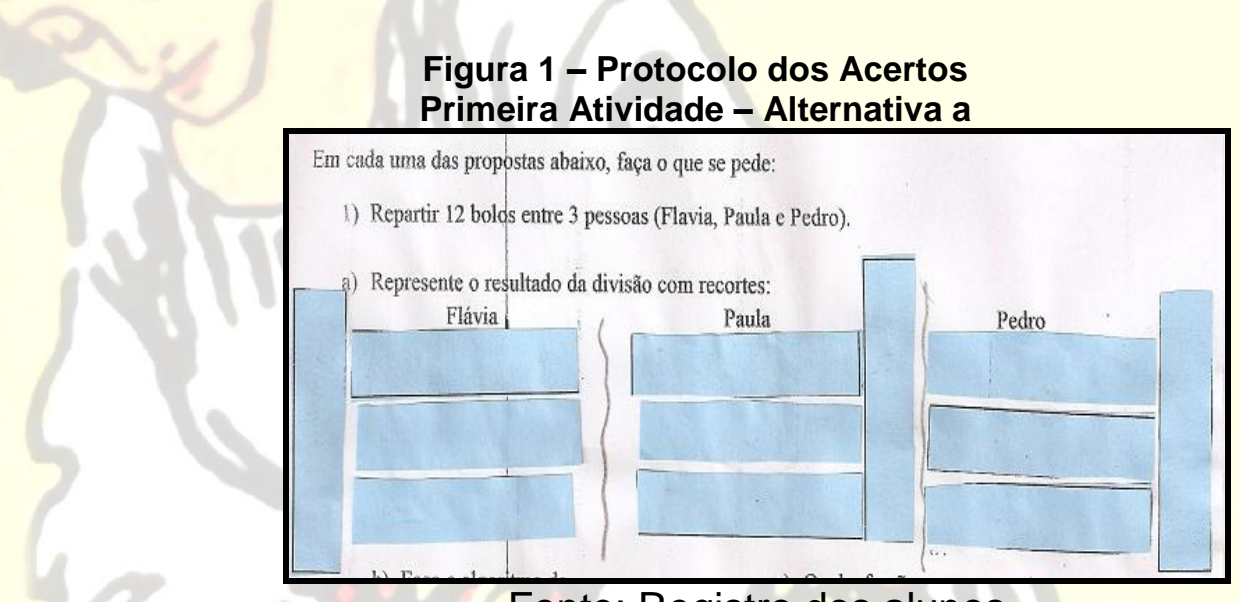

Fonte: Registro dos alunos

Já, o Erro Tipo 01, está relacionado ao número incorreto de retângulos repartidos entre as três pessoas:

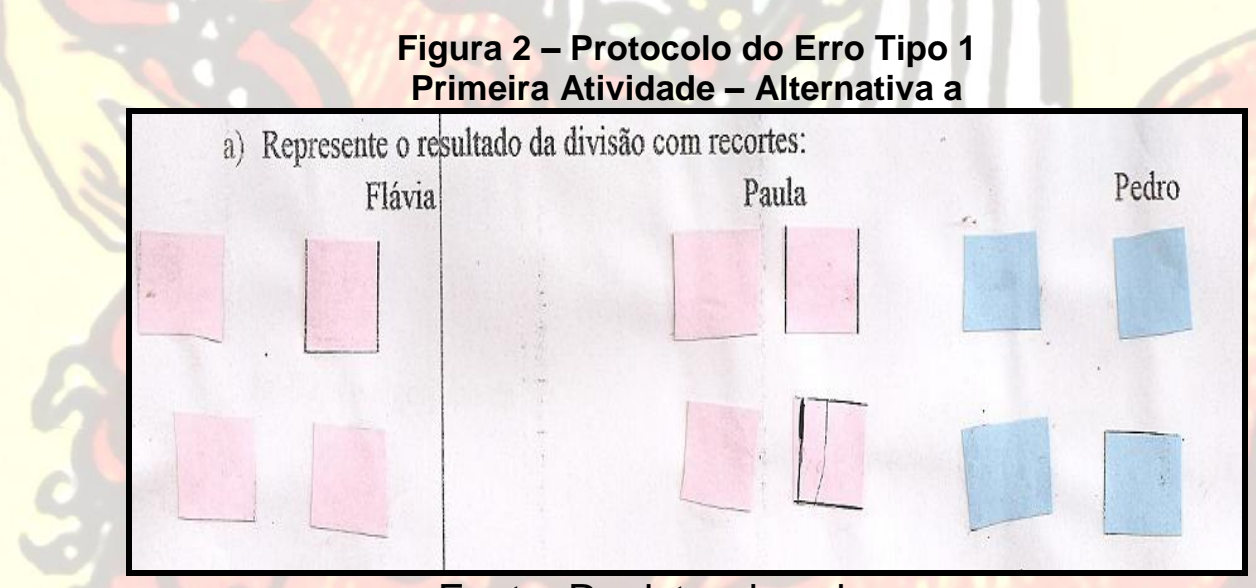

Fonte: Registro dos alunos

No caso, dois alunos sabiam que cada pessoa receberia 04 partes. O erro estava em não representar as partes inteiras.

Para o Erro Tipo 02, verificam-se as divisões desiguais entre as crianças da situação-problema proposta: 
Figura 3 - Protocolo do Erro Tipo 2

Primeira Atividade - Alternativa a

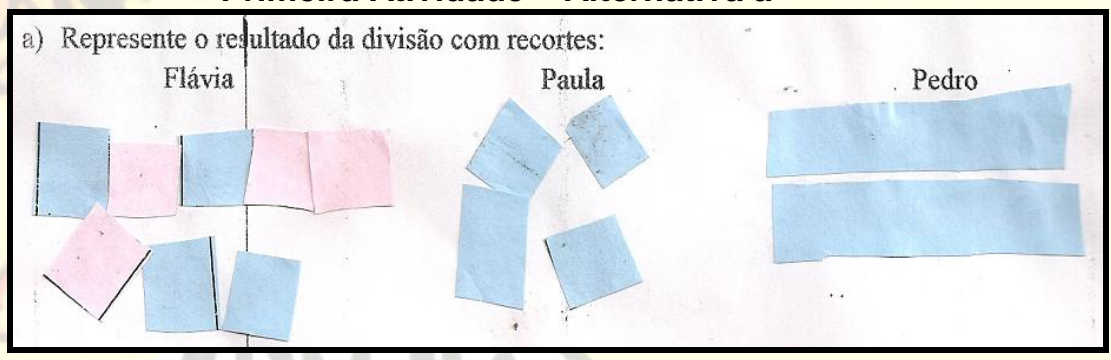

Fonte: Registro dos alunos

Constatamos um elevado índice de acertos nessa atividade. Essa dificuldade inicial foi descoberta posteriormente, quando os alunos, ao final, percebem que faltaram ou sobraram recortes. Após a mediação da pesquisadora, os alunos mostraram interesse em refazer as atividades.

Na próxima tabela, segue os resultados obtidos na segunda atividade:

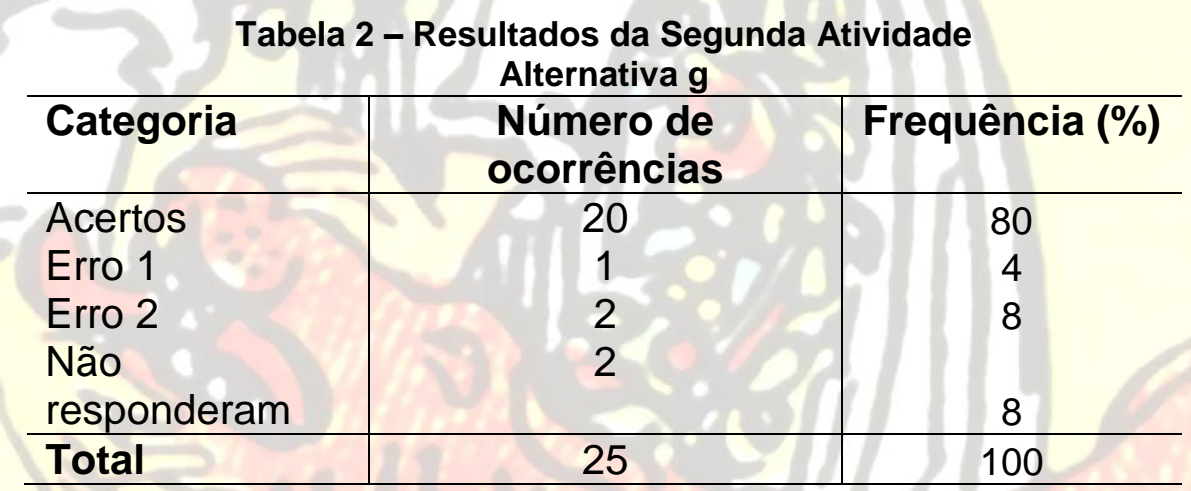

Segue uma representação dos acertos.

Figura 4 - Protocolo do Erro Tipo 2

Segunda Atividade - Alternativa $\mathrm{g}$

g) Represente 0 resultado da divisão com recortes:

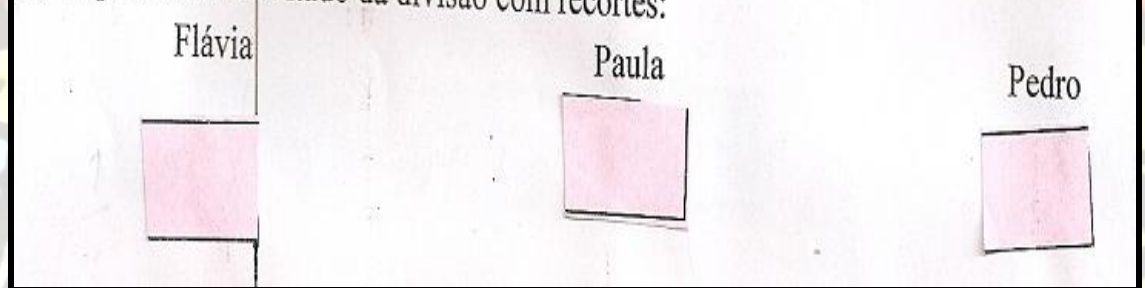

Fonte: Registro dos alunos 
A partir das informações acima, categorizamos o erro do tipo 01, como aqueles atribuídos aos alunos que deram um bolo inteiro para cada criança. $O$ correto seria dividir o bolo entre as três crianças:

Figura 5 - Protocolo do Erro Tipo 1 Segunda Atividade - Alternativa $\mathrm{g}$

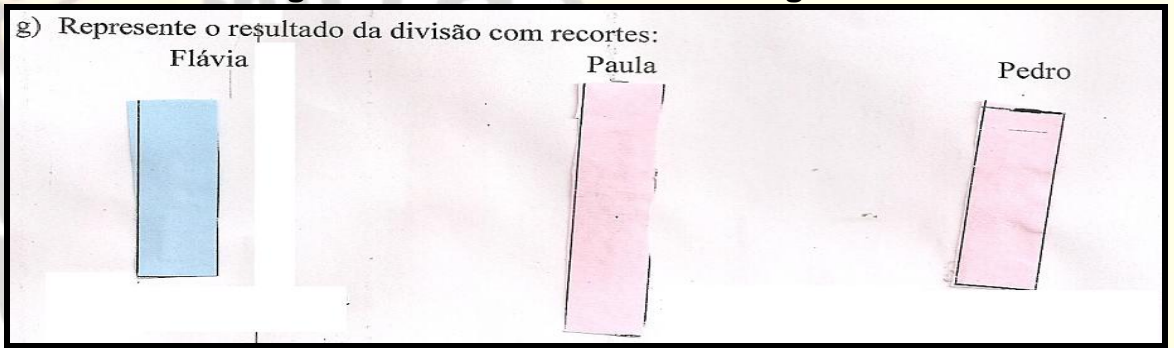

Fonte: Registro dos alunos

O erro do tipo 02 se relaciona em divisões desiguais entre as crianças da situação-problema proposta:

Figura 6 - Protocolo do Erro Tipo 2

Segunda Atividade - Alternativa g

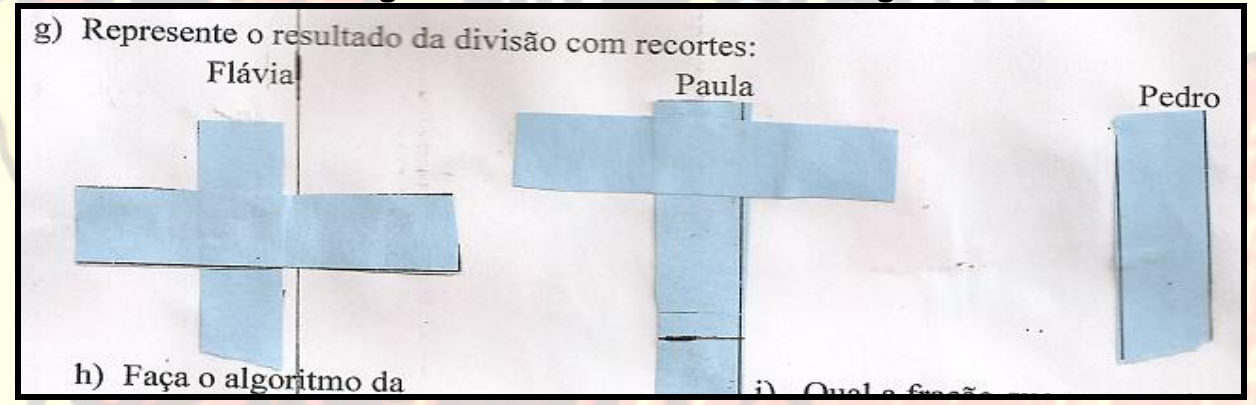

Fonte: Registro dos alunos

Constatamos um elevado índice de acertos nessa atividade. Porém, 02 alunos não tentaram resolver a questão proposta. Posteriormente, questionados pela pesquisadora, eles disseram que não tinham ideia de como começar e, por isso, não tentaram.

Na próxima tabela, segue os resultados obtidos na última atividade. 
Tabela 3 - Resultados da Terceira Atividade

Alternativa $\mathrm{m}$

\begin{tabular}{l|c|c}
\hline Categoria & Número de ocorrências & Frequência (\%) \\
\hline Acertos & 11 & $44 \%$ \\
Erro 1 & 2 & $8 \%$ \\
Erro 2 & 4 & $24 \%$ \\
Erro 3 & 3 & $12 \%$ \\
Não responderam & 3 & $12 \%$ \\
\hline Total & 25 & $100 \%$ \\
\hline
\end{tabular}

Observamos a redução significativa os acertos e aumento nos erros. Nessa fase, ocorreu uma diversificação maior dos erros.

Figura 7 - Protocolo dos Acertos

Terceira Atividade - Alternativa $\mathbf{m}$

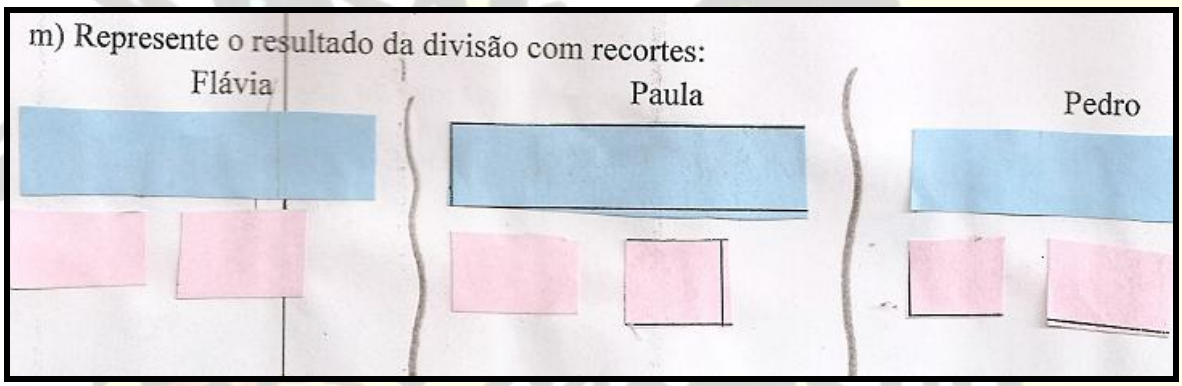

Fonte: Registro dos alunos

$\mathrm{Na}$ próxima atividade, representamos o Erro Tipo 01, realizado por dois alunos. Esses alunos associaram um bolo inteiro para cada criança, esquecendo-se dos bolos restantes que deveriam ser divididos.

Figura 8 - Protocolo do Erro Tipo 2

Terceira Atividade - Alternativa $\mathbf{m}$

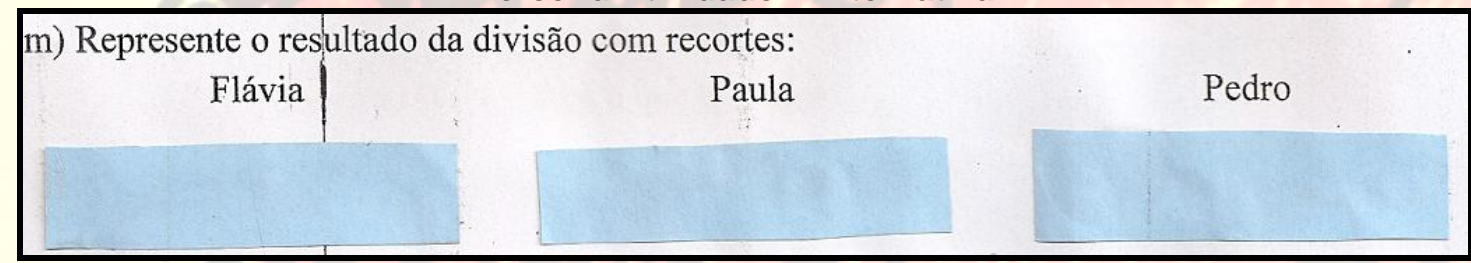

Fonte: Registro dos alunos

Já, o Erro Tipo 02 foi associado ao raciocínio dos alunos, em que foram dados três pedaços de bolos inteiros para cada criança, acrescidas de partes desiguais.

O Erro Tipo 03 foi associado ao raciocínio dos alunos que divide os cinco recortes em partes não iguais para as três crianças. 
A atividade que permitir conversões e tratamentos específicos deve levar o aluno a descobrir a solução para o pequeno problema. Para essa atividade, buscouse a descoberta para a resolução do problema através da manipulação com um material concreto.

No entanto, observamos nesse momento uma dificuldade muito grande por parte dos alunos para manipular o material concreto apresentado para a solução do problema. Assim, os alunos não atingiram satisfatoriamente os objetivos propostos para a Terceira Atividade.

De acordo com Duval (2013), esses erros podem ser analisados a partir de duas perspectivas totalmente diferentes. Primeiramente teríamos o erro, que estão relacionados à aquisição de um novo conceito ou procedimento. Nesse caso, temos os erros transitórios ou específicos, ainda nas palavras de Duval (2013).

Por outro lado, temos os erros que se fazem presentes sistemática e independentemente do conteúdo matemático. No caso, eles são transversais e bloqueiam qualquer ação de aprendizagem matemática. $O$ autor ainda salienta que as dificuldades mais profundas dos alunos não são provenientes apenas da falta dos conhecimentos matemáticos, mas, sim, de "um desconhecimento total dos gestos intelectuais, quer dizer, de operações semio-cognitivas, que são próprias da atividade matemática" (p. 21).

Utilizamos o material concreto para verificar se os alunos sabiam representar (resolver) o que o enunciado proposto em língua natural. Verificamos que $80 \%$ dos alunos souberam refletir sobre as problematizações que envolvem fração aparente ou própria. Para sanar a dificuldade em resolver a situação relacionada a uma fração imprópria seria necessário que o aluno convertesse o registro da língua natural para o figural (manipulação do material concreto), percebendo a necessidade de realizar o procedimento mental realizado nas frações aparentes e próprias.

Após esse procedimento mental, precisaria compreender as relações existentes entre as mesmas para identificar qual fração seria dividia e qual não seria. E, por sua vez, para verificar as relações existentes ou os possíveis procedimentos incorretos, os alunos poderiam realizar o algoritmo da divisão e perceber que 0 quociente indicava a possível parte inteira e o resto, a parte a ser dividida pelo número de crianças. 


\section{SEGUNDA ETAPA: ALGORITMO DA DIVISÃO}

Passaremos a apresentar os resultados dos registros das atividades, do item que retrata o algoritmo da divisão.

Neste ponto, foi necessário realizar a contagem do número de ocorrências de cada tipo de erros que agrupamos por semelhança. Era indispensável que o aluno "armasse" e efetuasse o algoritmo da divisão.

A nossa percepção é que muitos grupos de alunos não sabem efetuar a divisão. Porém, sabem representar, por meio da linguagem natural para a linguagem simbólica da divisão.

A seguir, o quadro retrata os resultados do algoritmo da divisão:

Tabela 4 - Resultado do Algoritmo da Divisão

\begin{tabular}{l|c|c|c|c|c|c}
\hline Categoria & $\begin{array}{c}\text { Número de } \\
\text { ocorrências } \\
\text { Atividade 1 }\end{array}$ & $\begin{array}{c}\text { Freq. } \\
\text { (\%) }\end{array}$ & $\begin{array}{c}\text { Número de } \\
\text { ocorrências } \\
\text { Atividade 2 }\end{array}$ & $\begin{array}{c}\text { Freq. } \\
\text { (\%) }\end{array}$ & $\begin{array}{c}\text { Número de } \\
\text { ocorrências } \\
\text { Atividade 3 }\end{array}$ & $\begin{array}{c}\text { Freq. } \\
\text { (\%) }\end{array}$ \\
\hline Acertos & 17 & 68 & 8 & 32 & 9 & 36 \\
Erro 1 & 4 & 16 & 8 & 32 & 5 & 20 \\
Erro 2 & 3 & 12 & 1 & 8 & 0 & 0 \\
Erro 3 & 0 & 0 & 1 & 4 & 2 & 8 \\
Não & 1 & 4 & 6 & 24 & 9 & 36 \\
responderam & 25 & $\mathbf{1 0 0}$ & $\mathbf{2 5}$ & $\mathbf{1 0 0}$ & $\mathbf{2 5}$ & $\mathbf{1 0 0}$ \\
\hline \multicolumn{2}{l}{ Total Quadro 1- Resultados da primeira questão, da primeira atividade }
\end{tabular}

No término das atividades, foram analisados os protocolos dos alunos e confrontados com o que se esperara como resposta. Nisso, concluímos que existem lacunas na aprendizagem, especialmente quanto à técnica de divisão.

Figura 8 - Protocolo dos Acertos - Algoritmo da Divisão

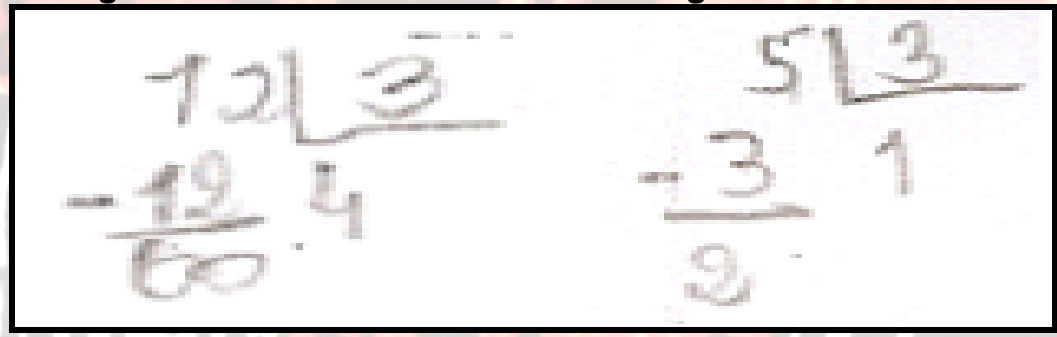

Fonte: Registro dos alunos 
Buscamos ilustrar as diferentes soluções dadas pelos alunos. A seguir, as categorias de erros são descritas. O Erro Tipo 01 foi associado ao raciocínio dos alunos em que se converteu o registro da língua natural em registro simbólico (algoritmo da divisão). O Erro Tipo 02 foi associado ao raciocínio dos alunos, em que se converteu o registro da língua natural em registro simbólico (algoritmo da divisão), porém, não se efetuaram os cálculos. O Erro Tipo 03 foi associado ao raciocínio dos alunos, em que não se converteu corretamente o registro da língua natural em registro simbólico (algoritmo da divisão).

Passaremos a apresentar os resultados dos registros das atividades, do item que retrata a representatividade da fração como forma de razão. Foi imprescindível realizar a contagem do número de ocorrências de cada tipo de erros agrupados por semelhança. Era preciso que o aluno compreendesse razão como parte/todo.

A seguir, o quadro abaixo retrata o resultado dessa representação:

Tabela 5 - Fração que representa a situação problema

\begin{tabular}{|c|c|c|c|c|c|c|}
\hline Categoria & $\begin{array}{l}\text { Número de } \\
\text { ocorrências } \\
\text { Atividade } 1 \\
\end{array}$ & $\begin{array}{c}\text { Freq. } \\
(\%)\end{array}$ & $\begin{array}{l}\text { Número de } \\
\text { ocorrências } \\
\text { Atividade } 2 \\
\end{array}$ & $\begin{array}{l}\text { Freq. } \\
(\%)\end{array}$ & $\begin{array}{l}\text { Número de } \\
\text { ocorrências } \\
\text { Atividade } 3 \\
\end{array}$ & $\begin{array}{l}\text { Freq. } \\
(\%)\end{array}$ \\
\hline Acertos & 9 & $36 \%$ & 10 & $40 \%$ & 6 & $24 \%$ \\
\hline Erro 1 & 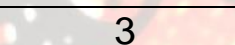 & $12 \%$ & 2 & $8 \%$ & 2 & $8 \%$ \\
\hline Erro 2 & 7 & $28 \%$ & 5 & $20 \%$ & 4 & $16 \%$ \\
\hline $\begin{array}{l}\text { Não } \\
\text { responderam }\end{array}$ & 6 & $24 \%$ & 8 & $32 \%$ & 13 & $52 \%$ \\
\hline Total & $x+x^{2}$ & $100 \%$ & 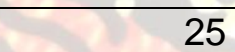 & $100 \%$ & 25 & $100 \%$ \\
\hline
\end{tabular}

Com essa atividade, os alunos que conseguiram acertar, sabem converter da linguagem natural para a linguagem simbólica da razão.

A figura abaixo, exemplificação dos alunos que acertaram a primeira e segunda atividade:

Figura 9 - Protocolo dos Acertos - Fração Representativa

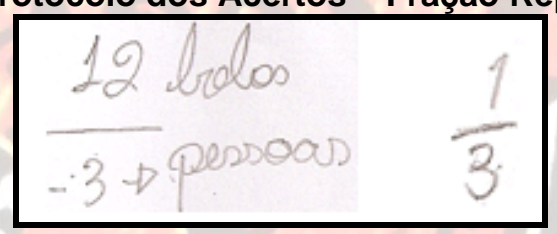

Fonte: Registro dos alunos 
Já, o Erro Tipo 01, retrata a inversão do numerador com o denominador, das primeira e terceira atividade:

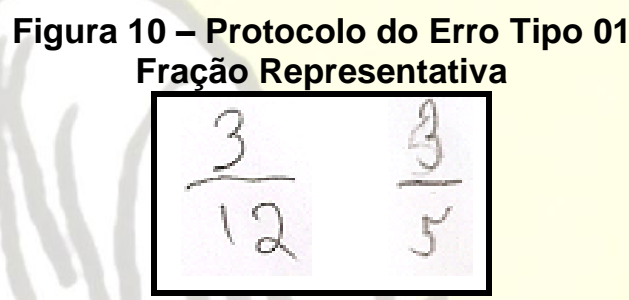

Fonte: Registro dos alunos

Categorizamos o Erro Tipo 02, a representação incorreta da situaçãoproblema, tanto na primeira quanto na segunda atividade.

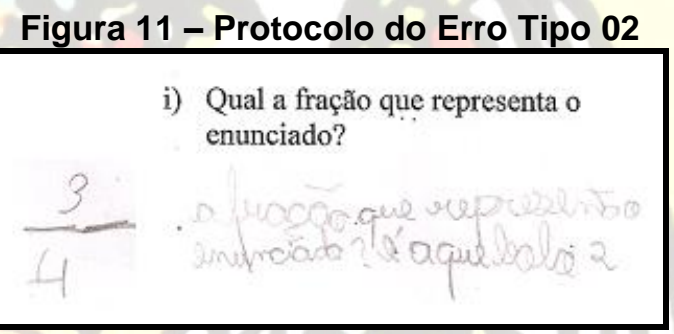

Fonte: Registro dos alunos

$\mathrm{Na}$ sequência, observamos se os alunos realizariam tratamento (registro da língua natural), interpretando o quociente nas operações realizadas.

\section{Quadro 6 - Significado do quociente}

\begin{tabular}{|c|c|c|c|c|c|c|}
\hline Categoria & $\begin{array}{l}\text { Número de } \\
\text { ocorrências } \\
\text { Atividade } 1 \\
\end{array}$ & $\begin{array}{l}\text { Freq. } \\
(\%)\end{array}$ & $\begin{array}{l}\text { Número de } \\
\text { ocorrências } \\
\text { Atividade } 2 \\
\end{array}$ & $\begin{array}{l}\text { Freq. } \\
(\%)\end{array}$ & $\begin{array}{l}\text { Número de } \\
\text { ocorrências } \\
\text { Atividade } 3 \\
\end{array}$ & $\begin{array}{l}\text { Freq. } \\
(\%)\end{array}$ \\
\hline Acertos & 10 & & 7 & & 2 & \\
\hline Erro 1 & 10 & & 11 & & 12 & \\
\hline $\begin{array}{l}\text { Não } \\
\text { responderam }\end{array}$ & 5 & 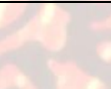 & 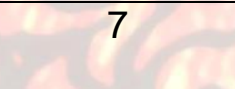 & & 11 & \\
\hline Total & 25 & $100 \%$ & 25 & $100 \%$ & 25 & $100 \%$ \\
\hline
\end{tabular}

Verificamos um percentual considerável dos erros, particularmente para o grupo de alunos que realizariam tratamento (registro da língua natural), interpretando corretamente o quociente nas operações realizadas.

Figura 12 - Protocolo dos Acertos - Interpretação do Quociente 
d) Qual o significado do quociente nesst divisão?

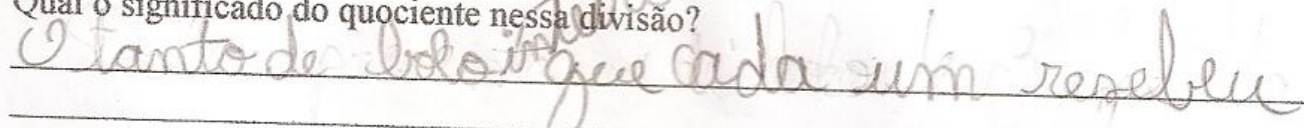

Fonte: Registro dos alunos

Figura 13 - Protocolo dos Erros - Interpretação do Quociente

k) Qual o significado do resto nessa divisão?

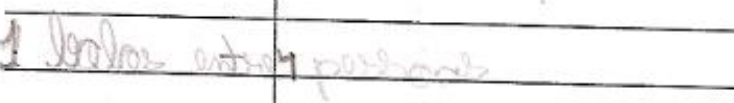

Qual o significado do quociente nessa divisão?

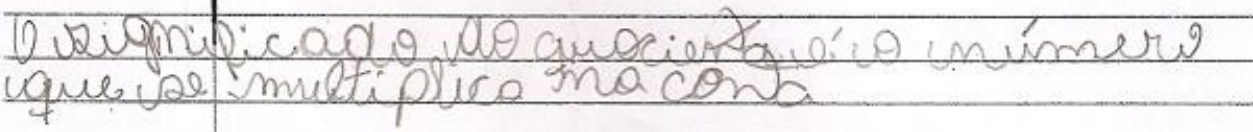

j) Qual o significado do quociente nessa divisão?

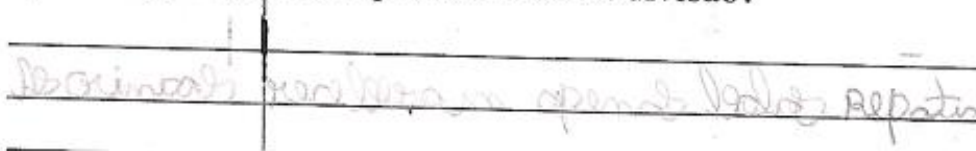

j) Qual o significado do quociente nessa divisão?

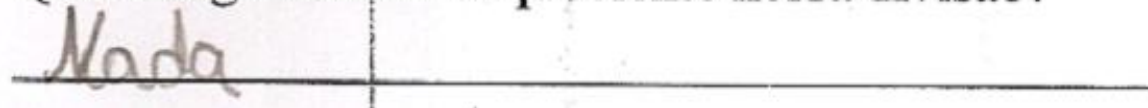

Fonte: Registro dos alunos

No momento, abordamos apenas essas análises. E podemos concluir que a atividade não obteve sucesso em seus resultados, pois, acreditamos que muitos ficaram fixados em tentar efetuar a divisão. O que nos leva a pensar que a terceira atividade se tornou a mais difícil, devido a uma lacuna na aprendizagem de alguns alunos.

\section{CONSIDERAÇÕES FINAIS}

A partir das observações tecidas acima, observamos que podem surgir situações em que os alunos conseguem aprender com uma atividade prática. Neste processo, porém, podem acontecer outras situações em que os alunos não consigam transpor para a linguagem matemática a ocorrência prática evidenciada. 
Isso ocorre, de acordo com Duval (2013), pelo fato de que o aluno não consegue compreender uma linha de raciocínio do ponto de vista matemático e nem tem condições de justificar uma propriedade, pois a atividade matemática, em que "o controle dos gestos intelectuais, específicos da atividade matemática, deveria ser o objetivo global de aquisição, e até mesmo o principal, sem ele, é impossível aplicar conhecimentos matemáticos em situações totalmente diferentes daquelas vistas em sala de aula" (DUVAL, 2013, p. 23).

Dessa forma, ter sucesso do ponto de vista matemático é encontrar um resultado certo matematicamente que responda a questão ou um problema. Por sua vez, do ponto de vista cognitivo, o sucesso é obtido a partir do momento em que o aluno consegue transferir um conhecimento apreendido em circunstâncias diferentes e sem conhecimento prévio para outras circunstâncias.

No primeiro caso, a avaliação se dá em uma escala de tempo pequena, já, no segundo, ela ocorre em uma escala de tempo maior, no caso, no decorrer dos anos. Para Duval (2008, apud LENARTOVICZ e GAERTNER), "isto acontece pelo desconhecimento das formas diferenciadas de representação de um objeto matemático". Segundo as autoras, é imperativo que os alunos saibam utilizar o que Duval salienta como imprescindível: "o uso dos tratamentos e das conversões entre os mais diferenciados registros de representação como forma de promover a compreensão do conceito matemático".

Ainda verificamos que precisamos reelaborar a atividade para que se completem as apreensões que Duval enfatiza. Em um futuro próximo, as atividades serão remodeladas e novamente apresentadas.

A partir dessas considerações, podemos concluir que os alunos não obtiveram "sucesso" no desenvolvimento, principalmente da terceira atividade proposta, tendo em vista a falta das operações semio-cognitivas necessárias para a atividade matemática, principalmente por não saberem efetuar divisões. 


\section{REFERÊNCIAS}

BARROS, L. G. X. Uma introdução ingênua à teoria dos registros de representações semióticas. Revista Ceciliana, v. 22, p.33-41, 2011.

DUVAL, R. Entrevista: Raymond Duval e a Teoria dos Registros de Representação Semiótica. Campo Mourão, RPGEM, Pr, v. 2, n.3, jul-dez.2013. Entrevista concedida a José Magalhães de Freitas e Veridiana Rezende.

FLORES, Cláudia Regina. Registros de representação semiótica em matemática: história, epistemologia, aprendizagem. Bolema, Rio Claro (SP), Ano 19, ํㅡ 26, 2006, $\begin{array}{llllll}\text { p. } & 77 & \text { a } & 102 . & \text { Disponível em }\end{array}$ http://www.ced.ufsc.br/claudiaflores/PESQUISA/textos publicados/Registros de representacao semi otica em matematica historia epistemologia aprendizagem.pdf. Acesso em 02/05/2014.

FLORES, Cláudia Regina. Registros de representação semiótica em matemática: história, epistemologia, aprendizagem. Bolema, Rio Claro (SP), Ano 19, № 26, 2006, $\begin{array}{llllll}\text { p. } & 77^{\circ} & \text { a } & 102 . & \text { Disponível }\end{array}$ http://www.ced.ufsc.br/claudiaflores/PESQUISA/textos publicados/Registros de representacao semi otica em matematica historia epistemologia aprendizagem.pdf. Acesso em 02/05/2014.

FREITAS, J.L.M.; REZENDE, V. Revista Paranaense de Educação Matemática RPEM, Campo Mourão, Pr, v. 2, n.3, jul-dez. 2013.

FRIEDERICH, D.M.J. A formação de professoras dos anos iniciais: um estudo sobre a concepção do conceito do número racional e suas representações. Dissertação de Mestrado. Programa de Pós Graduação nas Ciências ljuí/RS. 2010. p. 1-133. Disponível

em:

http://bibliodigital.unijui.edu.br:8080/xmlui/bitstream/handle/123456789/305/Danieli\%20Maria\%20Junges\%2 OFriederich.pdf?sequence=1. Acesso em 12/06/2014.

LENARTOVICZ, I. G.; GAERTNER, R. Aplicação da teoria dos registros de representação semiótica de Raymond Duval no estudo de funções polinomiais do $1^{\circ}$ grau no curso de Administração. Disponível em: http://webcache.googleusercontent.com/search?q=cache:epLafpHU26QJ:www.cibe m.org/extensos/403 1372460418 artigo cibem autora ilizete.doc $+\& \mathrm{~cd}=1 \& \mathrm{hl}=\mathrm{pt}-$ BR\&ct=clnk\&gl=br Acesso em 10/06/2014. 